\title{
Effect of co-inoculation of Brevibacterium iodinum RS16 and Methylobacterium oryzae CBMB20 on the early growth of crop plants in Saemangeum reclaimed soil
}

\author{
Kiyoon Kim, Chaemin Kwak, Youngwook Lee, and Tongmin Sa* \\ Department of Environmental and Biological Chemistry, Chungbuk National University, \\ Cheongju, Chungbuk 361-763, Republic of Korea
}

(Received: December 3 2013, Accepted: January 9 2014)

The objective of this study was to determine the effect of single and co-inoculation of plant growth promoting bacteria (PGPB) on early plant growth in Saemangeum reclaimed soil. Plant growth promoting Brevibacterium iodinum RS16 and Methylobacterium oryzae CBMB20 were inoculated on maize (Zea mays L.) and sorghum-sudangrass hybrid (Sorghum bicolor $L_{\text {.) }}$ grown in Saemangeum reclaimed soil. Single and co-inoculation of $B$. iodinum RS16 and $M$. oryzae CBMB20 increased plant height, dry biomass accumulation and macro-nutrient accumulation of maize and sorghum-sudangrass hybrid. M. oryzae CBMB20 treatment increased plant height in maize by $41.2 \%$ at 30 days after sowing (DAS), shoot dry weight and total dry weight compared to non-inoculated treatment. Macro-nutrient accumulation $(N$ and $P$ ) in maize roots was significantly increased with co-inoculation treatment, $\mathrm{K}$ and $\mathrm{Ca}$ content was significantly increased at $B$. iodinum RS16 treatment compared to non-inoculated treatment. Macro-nutrient accumulation (P, K, Ca and $\mathrm{Mg}$ ) in shoot was higher with $M$. oryzae CBMB20 treatment compared to non-inoculated treatment. In case of sorghum-sudangrass hybrid, co-inoculation treatment showed $33.7 \%$ increase in plant height compared to non-inoculated treatment at 30 DAS. M. oryzae CBMB20 treatment increased root dry weight and total dry weight, macro-nutrient accumulation in roots and $\mathrm{N}$, $\mathrm{Ca}$ and $\mathrm{Mg}$ accumulation in shoot compared to non-inoculated treatment. $P$ and $K$ accumulation in shoot was significantly increased at co-inoculation treatment compared to non-inoculated treatment. This pot culture experiment demonstrated that single and co-inoculation of $B$. iodinum RS16 and M. oryzae CBMB20 increased the early growth and nutrient accumulation of maize and sorghum-sudangrass hybrid.

Key words: Brevibacterium iodinum RS16, Maize, Methylobacterium oryzae CBMB20, Saemnangeum reclaimed soil, Sorghum-sudangrass hybrid
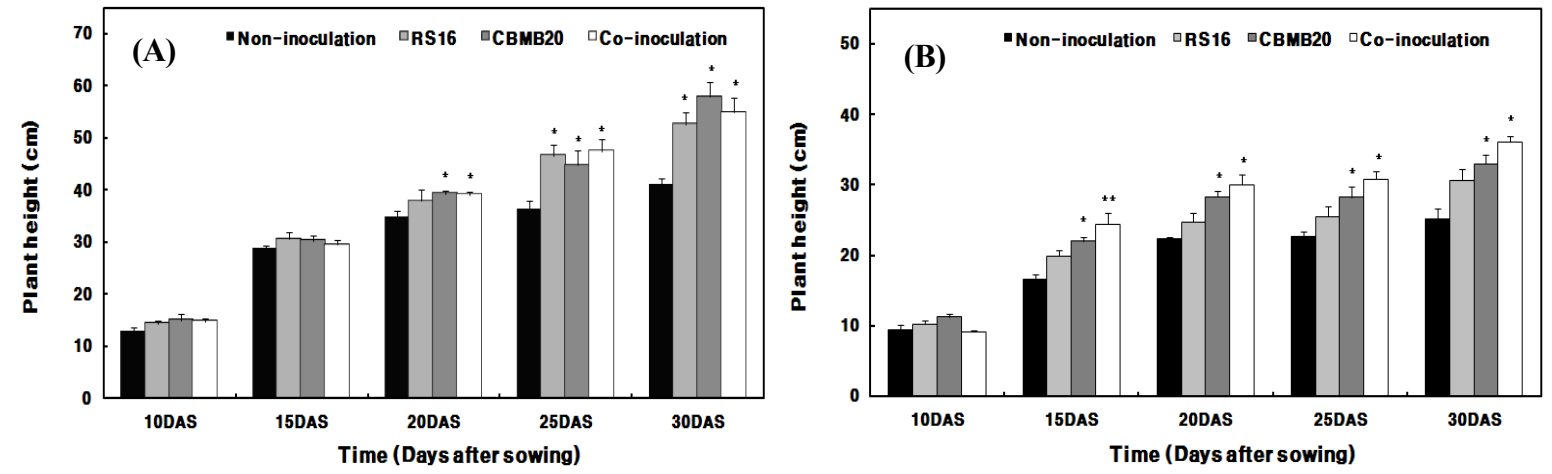

Single and co-inoculation of B. iodinum RS16 and M. oryzae CBMB20 increased early growth of maize (A) and sorghum-sudangrass hybrid (B) in Saemangeum reclaimed soil.

*Corresponding author : Phone: +82432612561, Fax: +82432715921, E-mail: tomsa@chungbuk.ac.kr

${ }^{\S}$ Acknowledgement: This work was supported by the research grant of the Chungbuk National University in 2011. 


\section{Introduction}

Saemangeum development project is a national project to build a global city as a frontrunner of green growth. It will create $283 \mathrm{~km}^{2}$ of reclaimed land and a lake as large as $118 \mathrm{~km}^{2}$ by constructing the world's longest $33.9 \mathrm{~km}$ sea dike (Lie et al., 2008). It is an estuary tidal flat on the coast of the West Sea in South Korea. It was dammed by the government of South Korea in April 2006 and is scheduled to be converted into either agricultural or industrial land (Ryu et al., 2010). Thirty percent of the land in Saemangeum has been set aside for agricultural proposes of which barely $17 \%$ are under low levels of salinity and thereby, sustainable for cultivation. The remaining $83 \%$ of the land has salt levels ranging from $0.3-1.0 \%$ and deemed not suitable for crop growth. The physical and chemical properties including organic matter $(0.1-0.5 \%)$, major and minor nutrients levels were very low (Choi et al., 2010). In theory, crop establishment and growth can be increased by removal of salt through mechanical or chemical methods and by improvement of nutrient status of the soil through application of organic and inorganic fertilizers. In practice, these processes entail exorbitant costs and pose negative impacts on the environment from use of inorganic fertilizers. A feasible and low cost option proposed is the use of microbial inoculants.

Benefits to plants from interactions with plant growth promoting rhizobacteria (PGPR) have been shown to include increases in seed germination rate, yield, leaf area (Mahaffee and Kloepper, 1994), root growth, shoot and root weights (Bashan et al., 2004; Bakker et al., 2007), nutrient uptake (Mantelin and Touraine, 2004), tolerance to abiotic stress (Yang et al., 2009). Other beneficial effects of PGPR strains include enhancing phosphorus availability (Rodriguez and Fraga, 1999); fixing atmospheric nitrogen (Bashan et al., 2004); sequestering iron for plants by production of siderophores (Bakker et al., 2007); producing plant hormones such as gibberellins, cytokinins, and auxins (Gutierrez et al., 2001); and synthesizing the enzyme 1-aminocyclopropane-1-carboxylate (ACC) deaminase, which lowers plant ethylene levels, thereby reducing environmental stress on plants (Glick et al., 2007).

Brevibacterium iodinum RS16 was isolated from West Coast soil of Yellow Sea, Incheon, South Korea and reported for its efficiency in improving red pepper plant growth under salt stress (Siddikee et al., 2011). This strain exhibits PGP characters like nitrogen fixation, IAA and ACC deaminase production. This halotolerant bacterium, having the ability to produce both ACC deaminase and IAA, was found to enhance root elongation and dry weight of canola to a greater extent than strains that produced ACC deaminase solely (Siddikee et al., 2010). The genus Methylobacterium includes a group of strictly aerobic, Gram-negative, pink pigmented, facultative methylotrophic (PPFM) bacteria characterized by their ability to utilize single-carbon compounds, like methanol and formaldehyde via the serine pathway, as well as a wide range of multi-carbon growth substrates (Green, 1992). Methylobacterium oryzae CBMB20 was isolated from rice stem and has been proven to have many plant growth promoting traits (Madhaiyan et al., 2007). This bacterial strain has the ability to produce ACC deaminase, which helps in the breakdown of ACC and reduce plant ethylene level, which inhibit plant growth at high concentration (Arshad and Frankenberger, 2002). Methylobacterium has also been reported to antagonize various phytopathogen and induced systemic resistance in plant (Madhaiyan et al., 2006; Indiragandhi et al., 2008). Some of the stains have been reported for growth enhancement in rice (Lee et al., 2006), tomato and red pepper (Ryu et al., 2006).

In this study, we have tested the single and co-inoculation effect of these two PGPB (B. iodinum RS16 and M. oryzae CBMB20) strains on maize and sorghum-sudangrass hybrid growth in Saemangeum reclaimed soil.

\section{Materials and Methods}

Bacterial strains and cultural condition For inoculum preparation, a single colony of B. iodinum RS16 grown on tryptic soy agar (TSA) media supplemented with 5\% $(\sim 0.85 \mathrm{M}) \mathrm{NaCl}(\mathrm{pH} 7.2)$ was transferred to $25 \mathrm{~mL}$ tryptic soy broth (TSB) and incubated at $30^{\circ} \mathrm{C}$ on a shaker $(150$ rpm) for $24 \mathrm{~h}$. After $24 \mathrm{~h}$ incubation, $1.0 \mathrm{~mL}$ of the culture $\left(1 \times 10^{8} \mathrm{cfu} \mathrm{mL}^{-1}\right)$ was transferred to $100 \mathrm{~mL}$ fresh TSB and allowed to grow for another $24 \mathrm{~h}$. M. oryzae CBMB20 single colony was grown in ammonium mineral salt (AMS) media with $0.5 \%$ sodium succinate was transferred to 25 $\mathrm{mL}$ AMS broth and incubated at $30^{\circ} \mathrm{C}$ on a shaker $(150$ rpm) for $72 \mathrm{~h}$. After $72 \mathrm{~h}$ incubation, $1.0 \mathrm{~mL}$ the culture $\left(1 \times 10^{8} \mathrm{cfu} \mathrm{mL}^{-1}\right)$ was transferred to $100 \mathrm{~mL}$ fresh AMS broth and allowed to grow for another $72 \mathrm{~h}$.

Pot experimental design Soil samples were collected from low salt affected sites of Gyehwa area in Saemangeum reclaimed land. The soil chemical properties were as follows: $\mathrm{pH}, 7.4$; Electrical conductivity (EC), $0.51 \mathrm{dS} \mathrm{m}^{-1}$; Organic matter (OM), $0.13 \mathrm{~g} \mathrm{~kg}^{-1}$; available $\mathrm{P}, 21.9 \mathrm{mg} \mathrm{P} \mathrm{P}_{2} \mathrm{O}_{5} \mathrm{~kg}^{-1}$. In this study maize (Zea mays L.) and sorghum-sudangrass hybrid (Sorghum bicolor L.) were used as experimental crops. These two crops showed high salinity tolerance in Saemangeum (Baek et al., 2010; Sohn et al., 2010) and other reclaimed land (Shin et al., 2007; Sohn et al., 2009). This experiment was done with four treatments (T1 - Control, T2 - RS16, T3 - CBMB20 and T4 - RS16 + CBMB20) using two crops (maize and sorghum-sudangrass hybrid). Plastic pots were filled with $2 \mathrm{~kg}$ Saemangeum reclaimed soil. 
Application of fertilizer and compost Chemical fertilizer was applied as urea, fused superphosphate and potassium chloride. Fertilizer application rate was determined based on the recommended basal chemical fertilizer application rate for maize (N : P : K, $\left.17.4: 3.0: 6.9, \mathrm{~kg}_{10} \mathrm{a}^{-1}\right)$ and sorghum-sudangrass hybrid (N : P : K, $20.0: 15.0: 15.0$, $\left.\mathrm{kg} 10 \mathrm{a}^{-1}\right)$. Chemical fertilizers were added 10 DAS. Compost prepared with $60 \%$ chicken dung, $20 \%$ bark and $20 \%$ saw dust was mixed with Saemangeum reclaimed soil at the rate of $20.0 \mathrm{~g} \mathrm{~kg}^{-1}$ in all the treatments.

Bacterial inoculation Before use in assays, maize and sorghum-sudangrass hybrid seeds were surface sterilized by immersing in $70 \%$ ethanol and $\mathrm{NaOCl}$. Bacterial inocula were prepared by growing $B$. iodinum RS16 and $M$. oryzae CBMB20 strains in their respective media. Seeds were then soaked in each bacterial suspension $\left(1 \times 10^{8} \mathrm{cfu}\right.$ $\mathrm{mL}^{-1}$ ) and were allowed to be imbibed by for $4 \mathrm{~h}$ at room temperature. The seeds were sown in plastic pots containing Saemangeum reclaimed soil. Subsequent inoculations with $B$. iodinum RS16 and M. oryzae CBMB20 were done 7-, 14-, 21- and 27 DAS. The bacterial strains were mass produced in $5 \mathrm{~L}$ fermenter (Bio cns $5 \mathrm{~L}$ lab fermenter, South korea). Single inoculation pots received $20 \mathrm{~mL}$ of culture $\left(1 \times 10^{8} \mathrm{cfu} \mathrm{mL}^{-1}\right)$ which is dissolved in $0.1 \mathrm{M}$ phosphate buffer solution $\mathrm{pH}$ 7.0. For co-inoculation pots, $10 \mathrm{~mL}$ of each culture was used.

Plant growth and nutrient accumulation Inoculation effect of $B$. iodinum RS16 and M. oryzae CBMB20 on plant height was recorded at 10-, 15-, 20-, 25- and 30 days after sowing. Plant biomass, in terms of root, shoot dry weight was recorded 30 DAS. Total nitrogen $(\mathrm{N})$ in roots and shoots was determined by a Kjeldahl Autoanalyzer 1030. Dried powdered plant samples (200 mg) were digested with sulphuric acid and potassium sulphate in a hot plate until a clear liquid was obtained. Total $\mathrm{N}$ in the digested samples were then analyzed with a Kjeldahl Autoanalyzer. Phosphorus (P) was analyzed by UV/Vis spectrophotometer. Other macro-nutrients like potassium $(\mathrm{K})$, calcium $(\mathrm{Ca})$, and magnesium $(\mathrm{Mg})$ absorbed by the plants were analyzed using Inductively Coupled Plasma Optical Emission Spectroscopy (ICP-OES, Optima 5300 DV, Perkin Elmer, USA). The data were expressed as uptake of nutrient by root and shoot on dry weight basis for individual plants.

Statistical analysis There was a total of 4 treatments, each containing 4 replicates in a completely randomized block design. Analysis of variance and LSD were calculated using SAS Version 9.1 (SAS 2009).

\section{Results and Discussion}

\section{Effect of B. iodinum RS16 and $M$. oryzae CBMB20} on plant height Single and co-inoculation of $B$. iodinum RS16 and $M$. oryzae CBMB20 on maize and sorghumsudangrass hybrid seedlings showed significant increase in plant height compared to non-inoculated (Fig. 1). Maize plant height observed at 10,15,20, 25 and 30 DAS, significant different over non-inoculated treatment was observed for M. oryzae CBMB20 and co-inoculation treatment after 20 DAS (Fig. 1(a)). Significant improvement was also observed between microbial treatment with $B$. iodinum RS16, $M$. oryzae CBMB20 and co-inoculation and that of the non-inoculated treatment at $28.3 \%, 41.2 \%$ and $33.9 \%$, respectively. In case of sorghum-sudangrass hybrid, at 15 DAS single inoculation of $M$. oryzae CBMB20 and co-inoculation treatments showed significant height increase compared to non-inoculated treatment (Fig. 1(b)). Co-inoculation treatment showed $33.7 \%$ increase in plant height compared to noninoculated treatment at 30 DAS. It was observed that single and co-inoculation of PGPB strains significantly improved

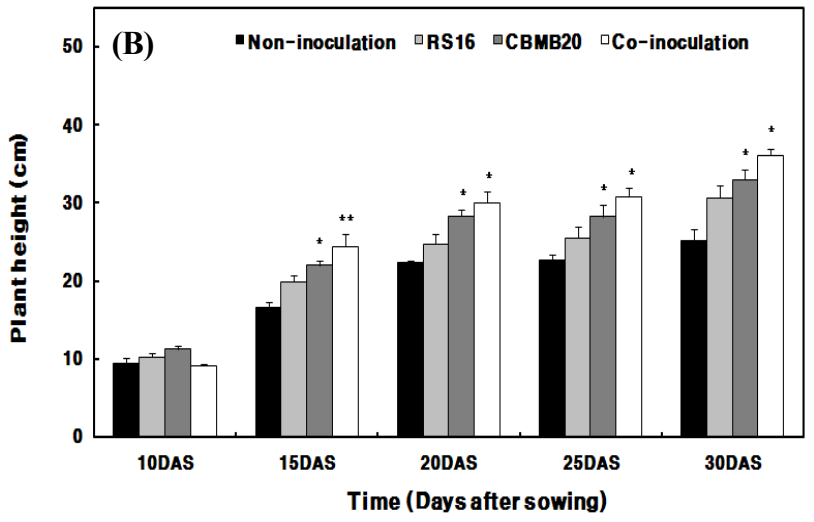

Fig. 1. Effect of B. iodinum RS16 and M. oryzae CBMB20 inoculation and co-inoculation on plant height of maize (A) and sorghum-sudangrass hybrid $(B)$ in Saemangeum reclaimed soil. Each value represents the mean \pm S.E $(n=4)$. Asterisk shows significant difference in values from the control, per group by LSD test $(P \leq 0.05) . * P \leq 0.05, * * P \leq 0.01$. 
plant growth. Several earlier studies also documented the single and co-inoculation increased plant height (Kim et al., 2012; Saber et al., 2012). We got the same kind of results with Adesemoye and Kloepper (2009), who reported that plant height significantly higher in bacterial inoculated treatment compared to non-inoculated treatment.

\section{Effect of $B$. iodinum RS16 and $M$. oryzae CBMB20} on dry biomass Single and co-inoculation effects of $B$. iodinum RS16 and M. oryzae CBMB20 showed significant increase in the maize and sorghum-sudangrass hybrid dry biomass accumulation in root, shoot and total plant (Fig. 2). Significant differences in root dry weight of maize was observed between inoculated and control plants (Fig. 2(a)). Higher shoot dry weight of maize was observed for M. oryzae CBMB20 treatment $(1.25 \mathrm{~g})$ followed by coinoculation treatment $(1.22 \mathrm{~g})$, with these two treatments having significantly increased shoot dry weight compared to non- inoculated treatment at $68.9 \%$ and $64.9 \%$, respectively. Total dry weight of maize significantly increased between treatments with $M$. oryzae CBMB20 (76.8\%) and co-inoculation treatment $(74.1 \%)$ compared to the non-inoculated treatment. In case of sorghum-sudangrass hybrid, significant increase in root $(0.16 \mathrm{~g})$ and total dry weight $(0.34 \mathrm{~g})$ was observed with single inoculation of $M$. oryzae CBMB20 compared to non-inoculated (Fig. 2(b)). Shoot dry weight of sorghumsudangrass hybrid co-inoculation $(0.21 \mathrm{~g})$ treatment showed higher values compared to other treatments. There were similarities in these results to those of Hernandez and Chailloux (2004), who reported that tomato grown in the greenhouse with two PGPR showed significantly higher dry weight compared to single PGPR treated plant. Several reports have been shown for the beneficial effects of single and co-inoculation of PGPR strains on dry biomass (Anandham et al., 2007; Saber et al., 2012; Aung et al., 2013).

Effect of B. iodinum RS16 and M. oryzae CBMB20 on the macro-nutrient accumulation in plant root and shoot Single and co-inoculation effects of $B$. iodinum RS16 and M. oryzae CBMB20 on macro-nutrient accumulation
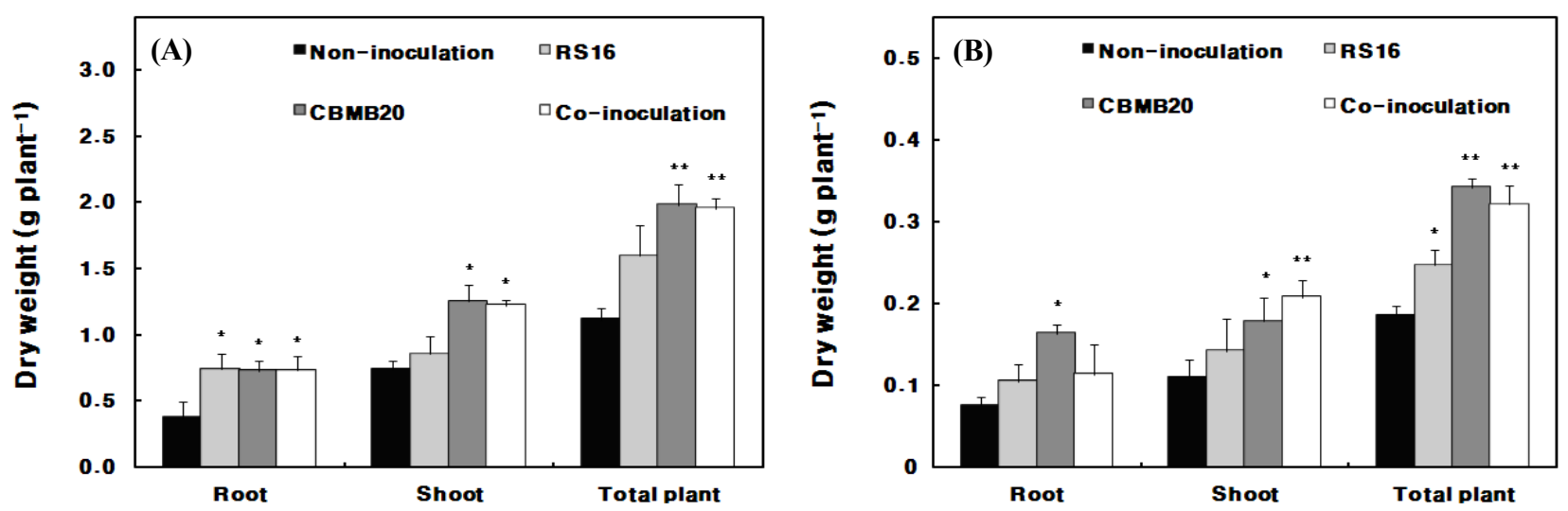

Fig. 2. Effect of B. iodinum RS16 and M. oryzae CBMB20 inoculation and co-inoculation on dry biomass of maize (A) and sorghum-sudangrass hybrid $(B)$ in Saemangeum reclaimed soil. Each value represents the mean \pm S.E $(n=4)$. Asterisk shows significant difference in values from the control, per group by LSD test $(P \leq 0.05)$. $* P \leq 0.05, * * P \leq 0.01$.

Table 1. Effect of B. iodinum RS16 and M. oryzae CBMB20 on macro-nutrient accumulation in root and shoot of maize.

\begin{tabular}{|c|c|c|c|c|c|c|c|c|c|c|}
\hline \multirow{3}{*}{ Treatments } & \multicolumn{5}{|c|}{ Root } & \multicolumn{5}{|c|}{ Shoot } \\
\hline & $\mathrm{N}$ & $\mathrm{P}$ & $\mathrm{K}$ & $\mathrm{Ca}$ & $\mathrm{Mg}$ & $\mathrm{N}$ & $\mathrm{P}$ & K & $\mathrm{Ca}$ & $\mathrm{Mg}$ \\
\hline & \multicolumn{5}{|c|}{ - } & \multicolumn{5}{|c|}{ 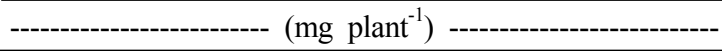 } \\
\hline Non-in & $6.7 \pm 0.3 \mathrm{~d}$ & $140.5 \pm 5.0 \mathrm{~b}$ & $9.7 \pm 0.5 \mathrm{~b}$ & $1.05 \pm 0.07 \mathrm{c}$ & $1.12 \pm 0.13 b$ & $17.1 \pm 1.0 \mathrm{c}$ & $223.3 \pm 1.1 \mathrm{~d}$ & $70.0 \pm 1.9 \mathrm{~b}$ & $0.90 \pm 0.13 \mathrm{c}$ & $1.87 \pm 0.16 b$ \\
\hline $\begin{array}{l}\text { B. iodinum } \\
\text { RS16 }\end{array}$ & $9.5 \pm 0.4 b$ & $239.5 \pm 20.0 \mathrm{a}$ & $31.8 \pm 1.3 \mathrm{a}$ & $2.87 \pm 0.05 \mathrm{a}$ & $2.97 \pm 0.16 \mathrm{a}$ & $19.1 \pm 0.4 \mathrm{~b}$ & $250.5 \pm 2.7 \mathrm{c}$ & $72.0 \pm 2.8 b$ & $1.11 \pm 0.09 \mathrm{bc}$ & $2.17 \pm 0.14 \mathrm{ab}$ \\
\hline $\begin{array}{l}\text { M. oryzae } \\
\text { CBMB20 }\end{array}$ & $8.5 \pm 0.3 \mathrm{c}$ & $229.9 \pm 17.3 \mathrm{a}$ & $27.4 \pm 2.6 \mathrm{a}$ & $2.15 \pm 0.22 b$ & $1.93 \pm 0.58 \mathrm{ab}$ & $23.2 \pm 0.2 \mathrm{a}$ & $385.0 \pm 8.6 \mathrm{a}$ & $111.4 \pm 5.9 \mathrm{a}$ & $2.66 \pm 0.20 \mathrm{a}$ & $2.69 \pm 0.15 \mathrm{a}$ \\
\hline Co-inoculation & $10.5 \pm 0.1 \mathrm{a}$ & $244.8 \pm 11.9 \mathrm{a}$ & $30.9 \pm 2.5 \mathrm{a}$ & $2.39 \pm 0.12 \mathrm{ab}$ & $2.77 \pm 0.14 \mathrm{a}$ & $24.6 \pm 0.4 \mathrm{a}$ & $327.9 \pm 2.7 \mathrm{~b}$ & $98.5 \pm 7.3 \mathrm{a}$ & $1.49 \pm 0.17 \mathrm{bc}$ & $2.25 \pm 0.24 \mathrm{ab}$ \\
\hline LSD $(P \leq 0.05)$ & 2.67 & 55.3 & 6.30 & 0.51 & 1.07 & 1.69 & 18.5 & 16.9 & 0.54 & 0.69 \\
\hline
\end{tabular}

Each value represents the average of four replicates per treatment \pm S.E. Significant difference according to LSD at $P \leq 0.05$ levels are indicated by different letter. 
Table 2. Effect of B. iodinum RS16 and M. oryzae CBMB20 on macro-nutrient accumulation in root and shoot of sorghumsudangrass hybrid.

\begin{tabular}{|c|c|c|c|c|c|c|c|c|c|c|}
\hline \multirow{3}{*}{ Treatments } & \multicolumn{5}{|c|}{ Root } & \multicolumn{5}{|c|}{ Shoot } \\
\hline & $\mathrm{N}$ & $\mathrm{P}$ & $\mathrm{K}$ & $\mathrm{Ca}$ & $\mathrm{Mg}$ & $\mathrm{N}$ & $\mathrm{P}$ & K & $\mathrm{Ca}$ & $\mathrm{Mg}$ \\
\hline & \multicolumn{5}{|c|}{ - } & \multicolumn{5}{|c|}{ - } \\
\hline Non-inoculation & $0.57 \pm 0.07 \mathrm{~d}$ & $14.0 \pm 0.3 \mathrm{c}$ & $3.5 \pm 0.3 \mathrm{~b}$ & $0.23 \pm 0.03 \mathrm{c}$ & $0.24 \pm 0.03 \mathrm{~b}$ & $2.40 \pm 0.05 \mathrm{c}$ & $62.5 \pm 1.0 \mathrm{~d}$ & $7.3 \pm 0.5 \mathrm{c}$ & $0.16 \pm 0.02 b$ & $0.44 \pm 0.04 \mathrm{~b}$ \\
\hline B. iodinum RS16 & $1.03 \pm 0.01 \mathrm{c}$ & $52.4 \pm 0.9 \mathrm{~b}$ & $4.3 \pm 0.3 \mathrm{~b}$ & $0.33 \pm 0.01 \mathrm{c}$ & $0.40 \pm 0.02 \mathrm{ab}$ & $3.65 \pm 0.04 \mathrm{~b}$ & $83.3 \pm 1.2 \mathrm{c}$ & $10.4 \pm 0.6 b$ & $0.30 \pm 0.03 \mathrm{ab}$ & $0.70 \pm 0.05 \mathrm{ab}$ \\
\hline $\begin{array}{l}\text { M. oryzae } \\
\text { CBMB20 }\end{array}$ & $1.65 \pm 0.05 \mathrm{a}$ & $62.0 \pm 0.2 \mathrm{a}$ & $6.3 \pm 0.7 \mathrm{a}$ & $0.77 \pm 0.13 \mathrm{a}$ & $0.55 \pm 0.09 \mathrm{a}$ & $5.27 \pm 0.10 \mathrm{a}$ & $100.2 \pm 2.4 \mathrm{~b}$ & $12.8 \pm 1.2 \mathrm{ab}$ & $0.38 \pm 0.06 \mathrm{a}$ & $0.99 \pm 0.12 \mathrm{a}$ \\
\hline Co-inoculation & $1.43 \pm 0.12 \mathrm{~b}$ & $47.9 \pm 2.5 \mathrm{~b}$ & $5.8 \pm 0.1 \mathrm{a}$ & $0.54 \pm 0.04 \mathrm{~b}$ & $0.53 \pm 0.02 \mathrm{a}$ & $5.14 \pm 0.02 \mathrm{a}$ & $121.9 \pm 0.3 \mathrm{a}$ & $14.5 \pm 0.7 \mathrm{a}$ & $0.31 \pm 0.03 \mathrm{ab}$ & $0.90 \pm 0.07 \mathrm{a}$ \\
\hline LSD $(P \leq 0.05)$ & 2.40 & 5.08 & 1.47 & 0.15 & 0.30 & 0.22 & 5.67 & 3.10 & 0.16 & 0.22 \\
\hline
\end{tabular}

Each value represents the average of four replicates per treatment \pm S.E. Significant difference according to LSD at $P \leq 0.05$ levels are indicated by different letter.

of maize root and shoot are summarized in Table 1. Significantly higher accumulation of $\mathrm{N}$ and $\mathrm{P}$ in roots of maize was observed among co-inoculated plants compared to non-inoculated plants. B. iodinum RS16 increased the content of $\mathrm{K}, \mathrm{Ca}$ and $\mathrm{Mg}$ in roots of maize. Microbial inoculation significantly increased the accumulation of macronutrient in roots. In maize, higher shoot $\mathrm{P}, \mathrm{K}, \mathrm{Ca}$ and $\mathrm{Mg}$ were observed in $M$. oryzae CBMB20 treatment and significantly differed from other treatments. Co-inoculation treatment showed significant difference in shoot $\mathrm{N}$ compared to B. iodinum RS16 and non-inoculated treatments. The effects of $B$. iodinum RS16 and M. oryzae CBMB20 inoculation and co-inoculation on sorghum-sudangrass hybrid macronutrient accumulation in roots and shoot are showed in Table 2. Single inoculation of $M$. oryzae CBMB20 and co-inoculation showed significantly higher $\mathrm{N}, \mathrm{P}, \mathrm{K}, \mathrm{Ca}$ and $\mathrm{Mg}$ accumulation in roots of sorghum-sudangrass hybrid compared to non-inoculated treatment. Higher N, P, K, $\mathrm{Ca}$ and $\mathrm{Mg}$ accumulation in roots was observed in $M$. oryzae CBMB20 treatment. Significant difference between microbial treatments and non- inoculated treatment was observed for shoot $\mathrm{N}, \mathrm{P}$ and $\mathrm{K}$ of sorghum-sudangrass hybrid. Likewise, M. oryzae CBMB20 treatment showed significantly higher shoot $\mathrm{N}, \mathrm{Ca}$ and $\mathrm{Mg}$ accumulation, whereas co-inoculation treatment showed significant difference in shoot $\mathrm{P}$ and $\mathrm{K}$ compared to other treatments. This kind of increase of nutrient accumulation by PGP bacterial strains was demonstrated under pot and field conditions (Han et al., 2006; Askary et al., 2009).

\section{Conclusion}

The results of this study proved that single and coinoculation of PGPB strains (B. iodinum RS16 and $M$. oryzae CBMB20) significantly improved plant growth of maize and sorghum-sudangrass hybrid in Saemangeum reclaimed soil. Moreover, macro-nutrient accumulation of maize and sorghum-sudangrass hybrid was significantly increased with single and co-inoculation of $B$. iodinum RS16 and M. oryzae CBMB20. The consistent improvement of maize and sorghum-sudangrass hybrid growth by $B$. iodinum RS16 and M. oryzae CBMB20 suggest the potential of these strains for large scale field application.

\section{References}

Adesemoye, A.O. and J.W. Kloepper. 2009. Plant-microbes interactions in enhanced fertilizer-use efficiency. Appl. Microbiol. Biotechnol. 85:1-12.

Anandhama, R., R. Sridarb, P. Nalayinic, S. Poonguzhalia, M. Madhaiyana and T.M. Sa. 2007. Potential for plant growth promotion in groundnut (Arachis hypogaea L.) cv. ALR-2 by co-inoculation of sulfur-oxidizing bacteria and Rhizobium. Microbiol. Res. 162:139-153.

Arshad, M., and Jr., W.T. Frankenberger. 2002. Ethylene: agricultural sources and applications. Kluwer Academic, New York, USA.

Askary, M., A. Mostajeran, R. Amooaghaei, and M. Mostajeran. 2009. Influence of the co-inoculation Azospirillum brasilense and Rhizobium meliloti plus 2,4-D on grain yield and N, P, K content of Triticum aestivum (Cv. Baccros and Mahdavi). American-Eurasian J. Agric. Environ. Sci. 5(3):296-307

Aung, T.T., B. Buranabanyat1, P. Piromyou1, A. Longtonglang, P. Tittabutr, N. Boonkerd, and N. Teaumroong. 2013. Enhanced soybean biomass by co-inoculation of Bradyrhizobium japonicum and plant growth promoting rhizobacteria and its effects on microbial community structures. Afr. J. Microbiol. Res. 7(29): 3858-3873.

Baek, N.H., J.H. Lee and J.H. Jeong. 2010. Production techniques of crop plants in reclaimed land. National Institute of Crop Science. 82-84.

Bakker, P.A.H.M., J.M. Raaijmakers, G.V. Bloemberg, M. 
Hofte, P. Lemanceau, and M. Cooke. 2007. New perspectives and approaches in plant growth-promoting rhizobacteria research. Eur. J. Plant Pathol. 119:241-242.

Bashan, Y., G. Holguin, and L.E. de-Bashan. 2004. Azospirillumplant relationships: physiological, molecular, agricultural, and environmental advances (1997-2003). Can. J. Microbiol. 50:521-577.

Choi, M.K., J.H. Lee, H.K. Park, B.I. Ku, K.D. Lee, M.K. Back, N.H. Back, Y.D. Kim, T.S. Park, W.Y. Choi, and J.K. Ko. 2010. Proper phosphate fertilization rate and grain yield for rice in South-west Gyehwado reclaimed saline paddy fields. Korea J. Intl. Agri. 22:131-133.

Glick, B.R., B. Todorovic, J. Czarny, Z. Cheng, J. Duan, and B. McConkey. 2007. Promotion of plant growth by bacterial ACC deaminase. Crit. Rev. Plant Sci. 26:227-242.

Green, P.N. 1992. The genus Methylobacterium. p. 2342-2349. In: A. Baloes, H.G. Truper, M. Dworkin, W. Harder, K.H. Schleifer (eds) The prokaryotes. Springer, Berlin Heidelberg New York, USA.

Gutierrez-Manero, F.J., B. Ramos-Solano, A. Probanza, J. Mehouachi, F.R. Tadeo, and M. Talon. 2001. The plant-growth promoting rhizobacteria Bacillus pumilus and Bacillus licheniformis produce high amounts of physiologically active gibberellins. Physiol. Plant. 111:206-211.

Han, H.S., Supanjani, and K.D. Lee. 2006. Effect of coinoculation with phosphate and potassium solubilizing bacteria on mineral uptake and growth of pepper and cucumber. Plant Soil Environ. 52(3):130-136.

Hernandez, M.I., and M. Chailloux. 2004. Las micorrizas arbuscularesy las bacterias rizosfericas como alternativa a la nutricion mineral del tomate. Cultivos Tropicales 25(2):5-12.

Indiragandhi, P., R. Anandham, K.A. Kim, W.J. Yim, M. Madhaiyan, and T.M. Sa. 2008. Induction of defense responses in tomato against Pseudomonas syringae pv. tomato by regulating the stress ethylene level with Methylobacterium oryzae CBMB20 containing 1-aminocyclopropane-1-carboxylate deaminase. World J. Microbiol. Biotechnol. 24:1037-1045.

Kim, K.Y., S.W. Hwang, V.S. Saravanan, and T.M. Sa. 2012. Effect of Brevibacterium iodinum RS16 and Methylobacterium oryzae CBMB20 inoculation on seed germination and early growth of maize and sorghum-sudangrass hybrid seedling under different salinity levels. Korean J. Soil Sci. Fertil. 45(1):51-58.

Lee, H.S., M. Madhaiyan, C.W. Kim, S.J. Choi, K.Y. Chung, and T.M. Sa. 2006. Physiological enhancement of early growth of rice seedlings by phytohormone producing of N2 fixing methylotrophic isolates. Biol. Fertil. Soils 42:402-408.

Lie, H.J., C.H. Cho, S. Lee, E.S. Kim, B.J. Koo and J.H. Noh. 2008. Changes in marine environment by a large coastal development of the Saemangeum reclamation project in Korea. Ocean. Polar. Res. 30(4):475-484.

Madhaiyan, M., S. Poonguzhali, J.H. Ryu, and T.M. Sa. 2006.
Regulation of ethylene levels in canola (Brassica campestris) by 1-aminocyclo-propane-1-carboxylate deaminase-containing Methylobacterium fujisawaense. Planta 224:268-278.

Madhaiyan, M., B.Y. Kim, S. Poonguzhali, S.W. Kwon, M.H. Song, J.H. Ryu, S.J. Go, B.S. Koo, and T.M. Sa. 2007. Methylobacterium oryzae spp. nov., a novel aerobic, pink-pigmented, facultatively methylothropic, 1-aminocyclopropan-1-carboxylate deaminase-producing bacterium isolated from rice. Int. J. Syst. Evol. Microbiol. 57:326-331.

Mahaffee, W.F., and J.W. Kloepper. 1994. Applications of plant growth promoting rhizobacteria in sustainable agriculture. $p$. 23-31. In: C.E. Pankhurst, B.M. Doube, V.V.S.R. Gupta, P.R. Grace (eds) Soil biota: management in sustainable farming systems. CSIRO, Melbourne, Australia.

Mantelin, S., and B. Touraine. 2004. Plant growth-promoting bacteria and nitrate availability: impacts on root development and nitrate uptake. J. Exp. Bot. 55:27-34.

Rodriguez, H., and R. Fraga. 1999. Phosphate solubilizing bacteria and their role in plant growth promotion. Biotechnol. Adv. 17:319-339.

Ryu, J.H., C.H. Yang, T.K. Kim, S.B. Lee, S. Kim, W.Y. Choi, N.H. Baek, S.J. Kim and D.Y. Chung. 2010. Elution patterns and distribution of salts from multi-layer reclaimed soils with subsurface layer of porous granules in the newly reclaimed Saemangeum tidal area. 19th WCSS. 121-123.

Ryu, J.H., M. Madhaiyan, S. Poonguzhali, W.J. Yim, P. Indiragandhi, K.A. Kim, R. Anandham, J.C. Yun, K.H. Kim, and T.M. Sa. 2006. Plant growth substances produced by Methylobacterium spp. and their effect on tomato (Lycopersicon esculentum L.) and red pepper (Capsicum annuum L.) growth. J. Microbiol. Biotechnol. 16:1622-1628.

Saber, Z., H. Pirdashti, M. Esmaeili, A. Abbasian and A. Heidarzadeh. 2012. Response of wheat growth parameters to co-inoculation of plant growth promoting rhizobacteria (PGPR) and different levels of inorganic nitrogen and phosphorus. World Appl. Sci. J. 16(2):213-219.

Shin, J.S., W.H. Kim, S.H. Y., and S. Seo. 2007. Study on optimum forage cropping system in reclaimed tidal land. J. Korea Grassl. Sci. 27(2):117-122.

Siddikee, Md.A., P.S. Chauhan, R. Anandham, G.H. Han, and T.M. Sa. 2010. Isolation, characterization, and use for plant growth promotion under salt stress, of ACC deaminaseproducing halotolerant bacteria derived from coastal soil. J. Microbiol. Biotechnol. 20(11):1577-1584.

Siddikee, Md.A., R. Bernard, B.R. Glick, P.S. Chauhan, W.J. Yim, and T.M. Sa. 2011. Enhancement of growth and salt tolerance of red pepper seedlings (Capsicum annuum L.) by regulating stress ethylene synthesis with halotolerant bacteria containing 1-aminocyclopropane-1-carboxylic acid deaminase activity. Plant Physiol. Biochem. 49:427-434.

Sohn, Y.M., G.Y. Jeon, J.D. Song, J.H. Lee, and M.E. Park. 2009. Effect of spatial Soil salinity variation on the growth of soiling 
and forage crops seeded at the newly reclaimed tidal lands in Korea. Korean J. Soil Sci. Fertil. 42(3):179-186.

Sohn, Y.M., J.D. Song, G.Y. Jeon, D.H. Kim, and M.E. Park. 2010. Effect of soil salinity and culturing condition on the maintenance of ridge and the growth of upland crops in the
Saemangeum reclaimed tidal land. Korean J. Soil Sci. Fertil. 43(5):407-417.

Yang, J., J.W. Kloepper, and C.M. Ryu. 2009. Rhizosphere bacteria help plants tolerate abiotic stress. Trends Plant Sci. 14:1-4. 